\title{
Breaking the Boundaries: Reimagining the Comparative Literary Method and Pedagogy in the Philippine Literature Classrooms
}

\author{
Honeylet L. Alerta \\ University of the Philippines Diliman
}

\begin{abstract}
At present, the Philippines is the only country that still implements the remote learning setup due to the COVID19 pandemic. This ongoing condition has placed educators to rethink how to scaffold the lessons and hone the demands of the 21st century amidst the current limitations of Filipino teachers and students. The challenge is to commit to a consistent dialogue in the virtual classroom without compromising the necessary skills, content, and learning competencies to hone the students' literary competence. Even before the pandemic, the discipline of comparative literature has had ongoing debates about its interdisciplinarity, its framework and method as a mode of inquiry in the academia, and its pedagogy in relation to teaching world literature. With the COVID19 pandemic, the compelling issues of the discipline resurface as another layer of challenge is apparent: engaging the students to read and examine the literary texts not just through close reading, but with an eye for parity in online distance learning. This perspective article seeks to showcase how, for now, the only comparative literature program in the country offered at the Department of English and Comparative Literature of the University of the Philippines Diliman can be integrated into teaching literature in universities and classrooms in the Philippines. More importantly, this paper seeks to propose ways to streamline the program in making up for the Philippine comparative literary studies through its method, and pedagogy.
\end{abstract}

\section{Keywords}

Comparative Literary Method, interdisciplinarity, comparative literary studies 


\title{
Breaking the Boundaries: Reimagining the Comparative Literary Method and Pedagogy in the Philippine Literature Classrooms
}

\author{
Honeylet L. Alerta
}

\section{Introduction}

Comparative literature is an interdisciplinary field whose practitioners study literature across national borders, across times, across languages, across genres, and the other arts (music, painting, dance, film, etc.), across disciplines (literature and psychology, philosophy, science, Ohistory, architecture, sociology, politics, etc.) (de Zepetnek 80). Hence, Comparative Literature is a trans-national, trans-medial, and transcultural discipline. It is a discipline built on pursuing connections between different aesthetic forms, cultural traditions, and ideas. Tracing those connections wherever they lead is what the comparatists mean by "comparison," whether they are following a theme across national and linguistic borders, studying film adaptations of literary texts, or inquiring into the places where disciplines intersect.

The "literature" in Comparative Literature refers both to literature as it is traditionally conceived - as fiction, drama, poetry, and literary nonfiction - and also to visual culture and cultural production more broadly ("What Is Comparative Literature? | Department of Comparative Literature"). Fundamentally the discipline of Comparative Literature is also a practice, a habit of learning, a way of studying literature, film, and culture without arbitrarily stopping at national or linguistic borders. The discipline recognizes that the world is interconnected, and is an opportunity for the comparative literary scholars to follow ideas across borders. Scholars of comparative literature are well informed of their responsibility to converse with the world with respect to the differences and commonalities, and understands what Susan Friedman posits that, "to refuse comparison in toto is to stick your head in the sand" (762). Such careful consideration on the nuances that each work of literature brings in the comparative lens makes the comparative literature different from other discipline in the humanities. 
Translation has also become vital in enabling the comparatists to conduct a comparative literary study. On a general lens, comparative literature both as a discipline and an academic program asks students for a language proficiency of more than one language other than their native tongue to begin the journey. In essence, the study of literary translation had to legitimize itself in the context of comparative literature by pointing to the significance of translations, not just as vicarious objects standing in for originals as best they can, but as significant counters in the symbolic economy and carriers of ideas, attitudes and values (Hermans 81).

This perspective essay seeks to show there are other practical strategies in which a literature teacher can better strategize the selection of the literary texts for their class. These strategies lie in the interrelationship among popular texts, literary works, and social issues in discussing literary texts through the digital interactive forum featured across online learning platforms. The essential understanding and critical literacy can still be fostered by pondering these reflective questions: 1) what concepts and learning outcomes do I want my students to exhibit given the pandemic-related limitations? and 2) How do I make my students demonstrate their critical literacy? Answering these two questions would better assist the literature faculty in determining the teaching and learning materials, assessment tasks, and strategies in teaching in the digital space.

\section{The Beginnings of Comparative Literature in the Philippines}

As of this writing, there are a total of forty-five (45) state universities and private colleges in the Philippines that offer undergraduate and graduate Literature programs in the Philippines. The variation and scope of the literature degrees are indicated by their labels such as the following: $\mathrm{AB}$ or BA in Literature, BA in English - Literature, $\mathrm{AB}$ in Literature Education, BSEd in Literature, $\mathrm{AB}$ in English Language and Literature, $\mathrm{AB}$ in Literary and Cultural Studies, $\mathrm{AB}$ in Philippine Literature, and $\mathrm{AB}$ in Literature and Performing Arts ("Schools Offering Literature \& Writing Courses in the Philippines"). Of these Philippine state universities and private colleges, only the Department of English and Comparative Literature (DECL) of the University of the Philippines Diliman offers an undergraduate and graduate degree in Comparative Literature.

For 111 years, the Department of English and Comparative Literature (DECL) of the University of the Philippines has been developing and teaching introductory courses in English, producing groundbreaking scholarship in language and literature; and fostering writers to become among the best in the country. According to the department's official website, the DECL was established in 1910 as the Department of English, under the College of Liberal Arts. The DECL's early years proved to be formative ground for Philippine literature in English (History | Department of English and Comparative Literature).

A series of transitions later formed the present DECL from the appointment of the first Filipino department head, Antonio Verbo, to the splitting the department, 
leading to the establishment of Art Studies and Speech Communication and Theater Arts departments.

The late 1960s and 1970s saw the department responding to the zeitgeist of political thought. Its faculty and students played critical roles in the resistance to martial law. Writers and activists from the department defined the literature of the period. In the 1980s and 1990s, the department charted new and exciting directions for language and comparative literary studies in the Philippines. It adapted a range of theoretical approaches, from Marxist theory to post-structuralism, from gender theory to postcolonialism.

Aside from the Comparative Literature program, the DECL also offers English Studies: Literature, English Studies: Language, and Creative Writing programs both at the undergraduate and graduate levels. These programs differ from comparative literature in the following aspects: the English Studies: Literature program explores the studies in British and American literatures within the contexts of historical, cultural, and literary developments in Britain and the United States; the English Studies: Language program highlights the theoretical and practical aspects of language use, covering integrative studies in language and literature; the Creative Writing program aims to train its students to various approaches and techniques in the writing of fiction, poetry, essay, and drama.

Today, among the DECL's faculty are the leading creative writers and literary scholars of the Philippines. Awarded with the Center of Excellence in English and Literature, the comparative literature program of the DECL can influence literature educators to concretize comparative literary studies in universities and classrooms in the Philippines (History | Department of English and Comparative Literature).

\section{The Issues in integrating Comparative Literary Method in the Philippine Classroom}

In the context of comparative literature in the Philippines, Amado Anthony Mendoza, in his article, "Resil Mojares and the Crisis of Comparative Literature in the Philippines," enumerates the discipline's three main criticisms: its too much reliance on close reading, the unquantifiable solutions that the method inspire in the past and existing critical literature, and its inability to solve real-world problems. These criticisms constitute the theoretical and methodological crisis of the field (Mendoza 81). Other comparative literary scholars such as Franco Moretti have fielded his alternative to close reading in his distant reading. Resil Mojares emphasizes that the problem of comparative literature in the Philippines is not much on the method, but of taking stock of our resources, the vast reserve of unutilized "literary capital." In Mojares' perspective, utilizing various works in Philippine literature can also influence the teachers' ways of engaging the students in analyzing our literary sources from multiple points, which is the core of comparative literature (Mendoza 89).

Due to the online distance setup, making practical strategies to follow a comparative literary approach in literature teaching to university students became 
challenging. For instance, given that students face their gadgets for online classes, teachers must consider de-loading the course requirements for students to handle. The troubling path is in designing the course syllabus in terms of representative sampling. If teachers do not have the luxury of time teaching undergraduate students a dozen great novels, then teachers can consider a dozen significant excerpts. The "unutilized" literary capital mentioned by Resil Mojares is presumably the literary works from Philippine regions that are available in libraries but may not be digitally archived. In my personal experience as a former senior high school literature teacher, I relied on my anthologies, both written in the Filipino vernacular with English translations such as Merlie Alunan's "Sa Atong Dila," a collection of Visayan poetry and songs. There are some texts that students must procure for their use in my class or I share in my presentation to scaffold the discussion in a comparative literary way. I admit that I am in the privileged position to acquire my materials and have the necessary devices to enrich the virtual reading experience of my class. I acknowledge that in the Philippines, there are many teachers who cannot have the opportunity to access good reading materials, let alone ask them to change their pedagogy. The literature teachers' access to instructional resources is crucial especially if they do not have the privilege to attend seminars and workshops that were designed to enrich their professional expertise in the teaching of literature. But the ultimate question for me is what the students carry away from the literature course. In a larger perspective, the objectives of teachers will vary according to schools and universities' resources and course offerings.

The essential strategy in which comparative literature can be taught is demonstrated in John Burt Foster Jr.'s "Cultural Encounters in Global Contexts: World Literature as a One-Semester General Education Course." Foster raises that the immediate challenge that university faculty have to address with their courses would be "how best to select texts that would deliver the faculty's approach to world literature to students" (Foster,_162). This dilemma was also apparent in the DECL of the University of the Philippines Diliman. In the webinar held by DECL on November 5, 2020, titled "Zooming Out: A Midterm Assessment of Best Practices in Teaching Online," Professor Patricia May Jurilla shared her experience as she reimagined her undergraduate concentration course in the digital space. She explained her cutting, designing, and adjusting her 'pre-pandemic list of readings and requirements to a new one and described this feat as not easy. "It was emotional and almost painful. Part of the difficulty of shortening the list is the feeling of responsibility to the texts and authors we teach as if we are their keepers. Teaching in the digital space is different from teaching in the classroom." ${ }^{2}$ Deciding to choose an author over the other and choosing a text over another seems challenging. Even other humanities faculty in other universities have experienced the same feeling of guilt. It was as if removing authors and texts to adjust their syllabus were unfair to other literary works. Yet, all of the texts listed have themes and contexts that are timely, relevant, and necessary to help the students achieve the skills that are in the curriculum. 
To guide the comparative literature faculty in redesigning their syllabi to suit the current needs in the pandemic time, they have to be informed of the fundamentals of online learning and prepare strategies that are inclined to harness the comparative literary skills of the students. The essential yet practical questions that a faculty must work on are: 1) What concepts and learning outcomes do I want my students to exhibit given the pandemic-related limitations? And 2) How do I make my students demonstrate their learning? Answering these two questions would better assist the comparative literature faculty in determining the teaching and learning materials, assessment task approaches, and even strategies in teaching in the digital space.

The pandemic-stricken globe has pushed universities to depend on the world wide web to hold 'webinars' via Zoom and Google Meet and as tools for procuring reading materials, navigating learning mode, and accessing learning service portals. In connection to this trend is the challenge of teaching comparative literature during the pandemic, especially in facilitating and maximizing the virtual teaching-learning experience. At present, the digital is embraced in disciplines and fields of the humanities, including comparative literature, although not by all: few comparativists call themselves digital (Tenen qtd. by de Zepetnek). ${ }^{3}$

Given the faculty member's varying levels of exposure, knowledge, and preparation to hold and implement appropriate strategies online, the comparative literary pedagogy using digital humanities is only demonstrated by several faculty members. Apart from these dilemmas, the resistance of the faculty to shift to digital for the fear of experiencing the complex transition that directly affects their pedagogical work in general. The present circumstance calls for comparative literary scholars to prepare in conducting researches, teaching, learning, and archiving digitally.

To encourage the humanities faculty to use the digital mode in teaching, they can be free to assign mechanisms to check and control the circulation and dissemination of humanities archival resources and disseminate comparative literary and cultural materials through the utilization of technology-assisted instruction. The accessibility to the original and the translated text in digital form offers the students the opportunity to hone their skill of looking at the text from different perspectives, thus enriching not only the understanding of the text but also opening up the perception of the students to multiple venues, interpretations, and languages. According to Steven Totösy de Zepetnek and Graziela Boruzko in their article, "Paradigm Shift in Comparative Humanities: Digital Humanities, Pedagogy with New Media Technology, and Publishing Scholarship Online," digitally archiving literary texts answer for the current demand to collect the most comprehensive range of materials, making the resources available for public consumption and retrievable in cheaper and more efficient means (de Zepetnek and Boruzko, -6$)$. For instance, the accessibility of uploaded literary texts, reviews, researches, and journals articles through the hyperlink feature of the Internet. The use of learning management systems such as BlackBoard Collaborate, Schoology, Perusall, and Congrea allow for a virtual classroom experience. These platforms can hold big data from the uploaded teaching materials, record sessions during synchronous sessions, and 
monitor the students' participation and performance through the virtually-saved assessment tasks uploaded by the faculty members. Enabling discussion forums using these digital learning platforms in a comparative literature class also demonstrates Steven Totösy de Zepetnek and Graciela Boruzko's dialogic mode." In the "dialogic mode," the educator conveys knowledge and receives feedback enriched and redirected to students, creating complete exchange cycles. Although shifting the comparative literary pedagogy to digital can be challenging to some university faculty members, it promises to place comparison in literary and cultural studies that highlights the myriad possibilities of textual permutation, which only increase in the Internet age (Edmond 242). ${ }^{4}$

\section{Bringing the Comparative Literary Method Closer in the Literature Classroom}

World literature is always associated with comparative literature because this body of knowledge plays an essential role in allowing students to read across time and culture. In discussing world literature in the comparative method, the students are trained to trace the unfolding of situations, characters, themes, and images across the centuries, in the work of writers who knew and responded to their predecessors (Damrosch 25). Similarly, John Burt Foster Jr., in his essay, "Cultural Encounters in a Global Contexts: World Literature as a One-Semester General Education Course," explains that world literature can broaden students' horizons even further and in ways that complement courses in world history, international relations, and anthropology" (Foster 163). World literature's advantage is that it is reflected and can be connected and studied across disciplines, a method that is conducted in a comparative literary study. Foster further expounds that,

World literature can promote a more intimate understanding of specific cultures, catalyze insights into underlying similarities and differences, and sharpen awareness of communication among cultures. It can also illuminate the intercultural dynamics through which these cultures are shaped and transformed in the first place. In general, it can give more substance and depth to a worldwide perspective on the human experience. (Forster 163)

The teaching and learning experience in a comparative literature class also reflects that the object of the study of world literature relies on the influence that the literary texts bring and the potentialities of literary discourse, rather than focusing on the work (Prettiman 380). ${ }^{5}$ The function of world literature and comparative literature realized by the students in the classroom provides avenues to interrogate and discuss the social issues reflected in different cultures and traditions and connect the texts to real-life situations. Furthermore, the function of world literature in the discipline of comparative literature is extended when the teachers use the plot as a vehicle for unfolding a strange new world to students, thereby creating literary worlds (Puchner, 258). ${ }^{6}$ 
It is worth noting that there is an ethical practice of comparison that must investigate the contexts and concepts explored in the literatures of the world. This idea is elaborated in Peter Hitchcock's "Ethics of World Literature." Hitchcock emphasizes that ethics, as practiced in world literature, is a method that seeks to define and redefine world literature by pushing the boundaries of a specific concept, yet knowing its untranslatability (368). Although untranslatability is a concern for comparatists, they can rely on identifying the texts' "universalizable" elements, a concept introduced by Gayatri Spivak. The 'singular' in a text, be it an image, tradition, or motif, is described as universalizable when particular to a specific locality, yet stir intellectual, moral, or emotional appeal to everyone regardless of race, gender, or culture, and beliefs.

Integrating the comparative literary method in a literature classroom in the pedagogical and scholarly aspects highlights the significance of being trained in examining the nuances found in the literary texts on a comparative lens. Going back to the essential value that comparative literary faculty must demonstrate in teaching literature, the conversation of David Damrosch and Gayatri Spivak in 2011 titled "Comparative Literature/World Literature: A Discussion with Gayatri Spivak and David Damrosch" stresses:

The bottom line of teaching literature [...] It is only a few (an unexpected joy for the teacher) who slide into being taught to play to lose, the only way you can be a teacher in the humanities. What is loss here? Do you want to lose when you play to lose [...] Gain to loss to gain to loss-- but what remains? (Spivak 470). ${ }^{7}$

Gayatri Spivak asserts the responsibility of the humanities teachers to strive for a well-trained mind to recognize and overcome their limitation when they read literatures that are not part of their heritage. This limitation speaks of the privilege that can hinder the teachers from assuming an unbiased understanding when they engage in humanities. To avoid this conflict, humanities teachers must "play to lose." It is the willingness to "unlearn" one's prejudices, beliefs, and assumptions and to learn how to occupy the subject position of the "other" knowledge. Hence, the teachers become distant yet connected to the cultural roots of the texts they read and teach. A scholar who achieved authentic learning is the one "who wins and loses." The act of freeing oneself from his assumptions and misconstrued ways of teaching texts that do not belong to his national heritage would allow space for the knowledge and understanding of the "other" to remain.

To help the literature faculty undo the limits of the traditional comparative study of literatures, David Damrosch shares his liberal approach in his literature classroom. He facilitates the discussion, but his students from different racial and cultural backgrounds lead the conversation by sharing their personal experiences and cultural practices (468). However, students' sharing might not be a legitimate source 
of knowledge. It is possible that some students may belong to a different race but grew up in a foreign country, so they may not have a full grasp of their heritage of origin. Hence, the faculty need to bridge the gap by designing and adopting digital texts in their pedagogical practice. My personal observation as a college instructor and a graduate student in literature is that, digital archives in literature are being made available to the online libraries of universities and are free of charge, provided that students get to enroll in a given semester. In the enriched virtual learning setup, Philippine state universities and colleges have invested in digital pedagogical materials that are more user-friendly and attract faculty to implement them into their courses. The production and availability of literature have increased exponentially over the past few decades, especially in the time of a global pandemic where texts have shifted to digital formats to suit the needs of distance learning. Faculty engaged in maximizing the use of digital archives can enable the students to concentrate their efforts in sharpening critical thinking skills while minimizing the time needed to retrieve sources, difficult if not impossible for many of them to access unless they are digitalized.

Likewise, the comparative literary method can also be applied when teaching Philippine literature in English and literature from other Philippine languages. Comparative literary scholar Resil Mojares explains that Philippine literature is a necessary constituent of world literature as it is heavily penetrated, driven, contaminated, and constituted by influences from other parts of the globe (229). Mojares offers a set of strategies in incorporating the comparative literary method in teaching Philippine Literatures to scrutinize the theoretical issues in the teaching of 'national' and 'regional' literatures and the learning approaches in addressing these issues are relevant at this time. For example, as a senior high school faculty teaching 21 st Century Literature from the Philippines and the World for four years, I was faced with the following dilemma: First, procuring the legitimate materials for my class especially those coming from other Philippine languages. Second, choosing the representative works from them, and covering another course at the second half of the term which is world literature in the 21st century. Third, compressing and plotting all of these lessons in an 80-hour period per semester. The practical solution that I learned throughout those years was to follow the principle of selecting the texts and think in terms of dynamic relations and determinations instead of a set categories and blocks of knowledge. As Mojares suggests, thinking in these terms should lead us away from certain parochialisms that would make of "Philippine literature" something intelligible apart from the "world" (230). In addition, the solution to include and balance the curriculum lies on integrating Philippine literature and World literature to see their necessary interrelations. Integrating Philippine literature and World literature is pedagogically possible and desirable by teaching world literature from and through our own literature (Mojares 230). The very idea of a "national literature" is a product of both "nationalizing" an "internationalizing" factors: the impulse to assert difference, based on a claim to a distinct culture, history, and identity; that this literature can only grow through a vital conversation with the rest of the 
world. To scaffold these goals in the Philippine literature classroom, the following comparative methods can be utilized:

First, approach Philippine literature and its dynamic relations to the world rather than by categorizing information. Use the contexts and themes from globalization to emphasize the dynamic of creating world-systems that gave rise to modern nations. To do this, teachers must be opened to reconceptualize the course that is focused on reading and of engaging in a world not one's own. Instead of surveying the texts. Aim for a more open selection of texts rather than a course limited to a fixed canon of "classics" or Great Works, one that excludes the literatures of much of the world (including the Philippines).

Second, review the idea and reality of "nation" and "world," or "nation" and "region," as they are vitally connected, mutually formative, and simultaneously existent. For example, discussing John Jack Wigley's memoir, "Home of the Ashfall" that speaks of his experience at the eruption of Mt. Pinatubo in 1991 can be compared to the elements, contexts, and local color to a selected work that was written at the onset of a volcanic eruption in another country. Use a comparativist approach in teaching world literature through Philippine literature, and vice versa.

Third, pairing of the text based on relations of direct influence, cultural homology, and thematic correspondence. For instance, I asked my students to read the novel "Smaller and Smaller Circles" (2001) by F.H. Batacan and watch its movie adaptation, and compare it to Budjette Tan's comics series, "Trese" (2005) and its Netflix adaptation. To push the discussion further, we analyze the social issues that are covered in those works and the recurring elements that make them representations of 21 st century literature. As a matter of fact, the students can also look for another crime fiction from another country and determine their similarity in terms of material conditions, social structure, and lived experience of the groups that produced them.

Philippine literature in English and in other languages can be taught with an eye for parity. Especially at the time of the socio-political and economic climate in our country, literature can be read both as social documents and be used as a tool to enrich the way of looking at, speaking about, and being in the world. In this way, the students would veer away from the tendency of treating literature a mere "reading" class, and their critical thinking skills can also be improved by connecting the text to real world scenarios. The strategy of activating the students' prior knowledge and engaging them in various socio-political, economic, psychological, and religious themes can also heighten their cross-cultural understanding and critical thinking to form an informed and unbiased evaluation of the issues and themes represented in the texts. The underlying conflicts, moral and social issues that influence the characters' decision-making and actions need more comparative literary analysis than close reading. In doing so, the student's prior knowledge of cultural contexts is tapped and be used to bridge their understanding of the context presented in the texts.

If in the case that the selected literary text for discussion is written in translation, the aim of facilitating comparative literary study must be guided by the practice of reading translations in their own right. One cannot fully understand comparative literary 
studies without considering the crucial role of translation in the international trade of literary texts. Literary capital also depends on what language a text is written in, thus increasing the importance of recognizing translation work within and outside nations where particular languages are dominant. Although some critics have questioned the supposed neutrality of translation and have pointed out its insidious role in consecrating literary value on texts fortunate enough to be recognized as worthy of translation, other scholars have claimed the many possibilities of translation counterhegemonic and as a means of promoting cultural conversations. There is indeed an uneven distribution of literary capital, but translation might help reduce the invisibility of dominated literature within national and international literary systems. In Lawrence Venuti's essay, "Teaching in Translation," he asserts that translations as texts "are imitative of the foreign texts they translate but relatively autonomous from those texts because of differences that are both linguistic and literary, structural and cultural" (Venuti 90). Hence, universalizable elements can still address cultural translation in the texts and be set as objects of analysis for comparative studies. Moreover, translation studies applied to national literatures mean learning to read translations and knowing how to speak for translation. Rather than treating translation as a form of scholarship, scholarship works in comparative literature must be considered as a form of translation. Published translation studies must be included and recognized in the humanities faculty's tenure, and promotion procedures since "translations make our work, work" (Klein 218). ${ }^{8}$

The importance of translation studies in the practice of comparative literary studies is addressed in both the undergraduate and the graduate comparative literature degree programs of the DECL. For the undergraduate and Master's degree programs, students must take 12 units of selected foreign language. In the doctorate level, students must be proficient in a selected Philippine language other than their mother tongue, and one foreign language to equip the students with the necessary competency in reading the texts in their original language. The students' multilanguage proficiency deepens students' knowledge of native and foreign languages and improves their linguistic and literary analysis skills.

\section{Enhancing the Literature Education in the Philippines Through the Comparative Literary Paradigm}

The interdisciplinarity of comparative literature may have boons and banes and is still being a subject of debate of comparative scholars, but in "Institutional Inertia and the State of the Discipline," Eric Hayot rethinks comparative literature as an academic program in a university through these questions:

1. What has determined that inside the nation, the pedagogy of the graduate program ought to look more or less everywhere the same? Is that good for students? Is it the product of serious thinking or the perpetuation of habits from another time? 
2. How can we proceed to be sure that we have figured out the best ways to produce knowledge, either as teachers or as writers? And would that certainty be more or less sure of itself-would it be more or less theorized, more or less the product of a particular close or severe philosophical consideration of the concepts involved in it were subject the same levels of intensity and thoughtfulness as to the forms of the culture studied elsewhere in the building? (13)

Discussing the ways of streamlining the comparative literature program is an excellent avenue to assess the discipline's state as an academic program and as a significant mark in the growth of comparative literary studies in the Philippine universities and classrooms.

The Comparative Literature degree offered at the DECL of the University of the Philippines Diliman stresses using Philippine and Southeast Asian Cultures as a matrix for comparative studies in literary theory, gender studies, etc. It encourages the study of works in the original language and simultaneously promotes translation as access to other cultures. The program also aims to enrich the student's encounter with varied cultural texts through a cross-cultural, intertextual approach to the various national/regional works of literature. The areas of concentration covered in this program are Asian Literatures, European Literatures, and Philippine Literatures in English and English Translation. To further strengthen the quality and influence of the comparative literature program in concretizing the comparative literary method in literature education in the Philippines, the following proposals can be considered:

First, establish broader connections to other universities abroad that offer comparative literature programs and venture on exchange programs that can promote experiential learning to the students, leading to conducting and presenting literary research locally and internationally. Doing so will highlight the integrity and the quality of the program and the graduates of the department. Given the online distance learning setup in the Philippines, scholarship grants offered in UP Diliman can help the students in financing the need to conduct and present studies in the national and international online conference. Scholarship grant such as the UP Presidential Scholarship open to second to $5^{\text {th }}$ year undergraduate, MA and PhD students offers a monthly stipend and book allowance renewable every semester. Through the scholarship grant, the students can have the means to participate in the online paper presentations concerning the state of comparative literature as a discipline and its importance in further enriching comparative literary studies in the Philippines. The DECL can also hold an annual webinar intended for secondary and university literature teachers in the Philippines, showing and highlighting the comparative method in further enhancing the teaching of literature and enriching the paradigms of the classroom discussion.

Second, the DECL can sustain the quality of the roster of faculty by investing in the potential of the comparative literature graduate students for university teaching opportunities. At present, the DECL has been in connection to the university's Office of 
the Vice President for Academic Affairs (OVPAA) in offering the Teaching Assistant/ Teaching Fellow Scholarship to their MA and Ph.D. students. ${ }^{10}$ Aside from the salary, book allowance, and free tuition, the scholarship also serves as an opportunity for the department to seek potential faculty members that share the same vision. The DECL can hone the teaching assistants (MA students) and teaching fellows (Ph.D. students) to be competent academically and professionally by sharing an undergraduate or a graduate class in the standards set by the university. In addition, graduate students can also determine how to develop a comparative literature course discussion into a broader avenue for research interests. For example, the comparative literature graduate students who are also practicing literature teachers can adapt strategies and assessment tasks that use the comparative method in scaffolding classroom discussions. Thus, this will refine the integration of pedagogy and methods in comparative literature to the growing body of emerging genres in Philippine Literature in English and in other Philippine languages.

The third way of streamlining the comparative literature program will be on revising the areas of concentration to keep up with the trends in media and cross-cultural experiences of Filipinos in the 21 st century. Courses such as South Korean Literature, 21st Century Literature, and Transmedia in Literature may enrich the literary and cultural references in the current program of comparative literature. A review of the number of courses required to be taken to recalibrate the number of semesters the students will have to spend to complete the program, yet not compromising the depth of its content, must be made. Based on the 2007 revised checklist for the Ph.D. Comparative Literature Program of UPD. Department of English and Comparative Literature, a graduate student must: choose one from among the areas of concentration: Comparative Literary Theory, Criticism, and History; Philippine literatures in English and Philippine Regional Literatures in English Translation; Literature and the Arts; Literature and the Social Sciences; and Literary Translation. Next, graduate students have to take and pass a qualifying examination after taking at least nine units of the core subjects. Then, 15 units for the chosen area of concentration, six units of interdisciplinary electives, take and pass a foreign and vernacular language exam, comprehensive exam, and write and defend a dissertation. The modification of the requirements can be calibrated by converting the required number of units for course subjects to research courses. In this way, the graduate students can finish the program with lesser required units but better grounding in conducting and writing their comparative literary research.

Fourth, the DECL may look into replacing the required qualifying examination for graduate students after having passed nine units of the course and instead require them to write a research article based on any specialization courses taken. The article must be published in a reputable journal, either locally or internationally. In Li Weifang's essay "The Mission of Research on Globalization and Comparative Literature," the objective of comparative literary study highlights the need to facilitate communication, dialogue, and understanding of multicultural contexts to which literatures originated (Weifang, 40). Since the onset of the online conferencing tools, free webinars held locally and internationally have been abundant, opening opportunities for 
the students to present and share their critiques. Furthermore, comparative literature graduate students can frame their research to form an effective dialogue with other literary educators in the Philippines to address the inevitable challenges as the world strives to develop a community of shared futures. The DECL can also establish stronger ties with UP Diliman's College of Education to offer courses from the comparative literature program to Education majors.

Not only will the students' research works be counted as literary production of the department, but also as a good test for the graduate students to manifest their mastery of the paradigms of comparative literature. The areas such as Areas and Methods in Comparative Literature, Literary Theory and Criticism, and Philippine Literatures in English can be the areas of researches. Graduate students can also exercise their ability to analyze various literatures using a systematic comparison method and not just a study of differences (Moretti, qtd. by Heise, 280). The research studies to be published by the graduate students can dwell on challenging the isolation of national literatures, relativizes national myths, and recovers the ignored or marginalized texts, writers, and minority literatures" (Dominguez, 45). Producing and publishing a comparative literary study can serve as an opportunity for graduate students to explore other growing paradigms in comparative literature and contribute to the country's growth of comparative literary studies.

Fifth, encouraging literary production can show how many career choices strongly support undergraduate and graduate degrees in comparative literature (Spivak, 220). Comparative literature is one of the effective ways to conduct an inclusive dialogue among different countries and spread positivity from the cultural and academic levels (Weifang, 44). Part of the training in studying comparative literature also involves communication and resonance between national situations. Literary affinities may arise between nations and peoples trying to stand on their own on the world stage. Undergraduate and graduate students can 'experience' being global by cultivating imagination and sensibility, learning about different cultures, and nurturing a sensitivity to commiserate with all those suffering in the world (Wang,154).

Sixth, comparatists will have to demonstrate new ways of preserving and asserting the value in synthesizing complex and discrepant information that was never designed to be drawn together and making sense exactly where existing canons and methods fail us. That is how we can keep comparative literature's specific difference open in a shrinking humanities domain (Dominguez-Saussy, 28).

Going back to the questions posted by Eric Hayot on the institutional inertia of comparative literature, it will be challenging in the Philippine academic context to suddenly take a pedagogical shift just for the sake of applying and sustaining the comparative literary method in the Philippines. For instance, given the economic limitations of the literature teachers, and admittedly, the time to be spent on redesigning a course syllabus towards a comparative literary pedagogy is time and resource consuming. The most practical solution that I can see aside from having the literature teachers reflect about their goals in teaching the discipline is to dwell on the richness of 
transmedia sources such as adaptations of texts that were made available via Netflix, YouTube, and other online media channels to gauge their students' attention on the explicit and implicit cultural, gender, and social issues that are prevailing in the works. The teachers' interest as well on the topics to be discussed in relating them to the students' understanding of the text can lead to a fruitful discussion of the text and can also enrich the students' critical literacies. As literature teachers, it is important to go back to the most essential question to direct our teaching of literature in a comparative way: "What is it that we would like our students to take away from our literature course? ${ }^{11}$

All aspects considered, responding to the crisis faced by comparative literature in the Philippines from pedagogical, scholarly, and institutional angles helps us see its potential to integrate the comparative literary methods in universities and classrooms in the Philippines. Similarly, recalibrating the vision and comparative literary approach in teaching literature helps us see it as a significant discipline in the growth of literary and cultural studies in the Philippines.

\section{Notes}

1. Steven Totosy de Zepetnek explained that the marginalization of the literature study stems from the neglect and lack of rational, inclusive, methodologically precise attention in operationality and functionality that results in inaccuracy.

2. At present, the University of the Philippines Diliman faculty is bound to prepare course packets to accommodate all undergraduate and graduate students, especially those who do not have the means to attend and participate in the synchronous online sessions.

3. The COVID19 pandemic has forced educators globally to shift their classrooms online, making them experience a sense of being hurried that exceeds their comfort zones. Steven de Zepetnek and Graciela Boruzko suggest that university technicians bridge the influx of platforms into disciplines, support individual faculty, and relay faculty responses to technical providers. Understanding needs to occur since pedagogical rhetoric and practices and technological rhetoric and practices do not often coincide.

4. Digital pedagogical materials are becoming more user-friendly and are attracting faculty to implement them into their courses, increasingly incorporating the features that faculty request. At present, several universities and colleges have evaluated the impact of changes on faculty and created the proper culture of innovation that all constituents can handle.

5. C.A. Prettiman confronts the dilemma that comparative literary professors face in designing a World Literature course. She enumerates the possible criteria for including a literary text in a syllabus so that students can acquire an educated literary taste.

6. In the essay, "Teaching Worldly Literature," Martin Puchner stresses that students' direct experience reading literature for the first time is the experience of entering a world - what rules apply there, and how the characters confront those. Hence, teachers are encouraged to practice the 
pedagogy of world-creation in a world literary discussion to help the students engage in a comparative dialogue.

7. The conversation between David Damrosch and Gayatri Chakravorty Spivak in 2011 demonstrated their principles on teaching world literature and comparative literature. Damrosch appears to be a liberal humanist when he shared that in his classroom, he allows his multicultural students to share their socio-cultural practices to probe their discussion of the literary texts. This pedagogical practice has a lapse, according to Spivak. She then proposed a test to be taken by the multicultural students to determine their linguistic capacity and cultural knowledge to qualify them as the appropriate informant of class.

8. In the article titled, "Reading and Speaking for Translation: Deinstitutionalizing the institutions of literary studies," Lucas Klein emphasizes that at present, many of the trends and topics that have first shown up in comparative literature deserve better dissemination in all departments of literary studies in the future, such as the relationship between translation and national literatures. To resolve this dilemma, Klein encourages scholars of literature to promote translation studies by giving academic credit for published translations. Furthermore, he points out that rather than treating translation as a form of scholarship, the academe must consider scholarship as a form of translation since the essential mechanism of understanding texts in their various contexts is already a work of translation.

9. Avram Alpert calls the attention of the academe to rethink academic labor as constituted by innovations in form, remapping scholarship as performance. He further elaborates that the formcontent of aesthetic experience is always a part of what the humanities scholars do, and it is time to engage it more broadly and more conscientiously

10 UP Diliman's OVPAA offers a Teaching Assistant Program. Teaching Assistants are either Teaching Associates (TAs) -Master's students, or Teaching Fellows (TFs) - Ph.D. students, who are pursuing their studies half-time and are teaching half-time. They are postgraduate student scholars and not contractual employees of the university. The program aims to give the finest students of UP the opportunity to share their knowledge and skills through teaching even while they are studying. The TAs and TFs also contribute to reducing the teaching load of faculty in the University.

11 This perspective essay is an enhanced version of the talk that will be given in ASEAN on critical literacy and the role of creating dialogues in an online discussion forum to be presented on December 3, 2021. 
Honeylet Alerta, Breaking the Boundaries: Reimagining the Comparative Literary Method and Pedagogy in

the Philippine Literature Classrooms

\section{Works Cited}

Alpert, Avram. "Performative Scholarship." Futures of Comparative Literature: ACLA State of the Discipline Report, edited by Heise, Ursula K. et al., Routledge. 2017, pp. 17-18.

Damrosch, David. "Reading Across Time, Reading Across Cultures." How to Read World Literature, Wiley and Blackwell, 2009, pp. 24-64. https://hunlit.lett.ubbcluj.ro/data/tszl/2016/DD.pdf

Tötösi de Zepetnek, Steven. "A New Comparative Literature as Theory and Method." ders.: Comparative Literature. Theory, Method, Application. Textxet: Studies in Comparative Literature 18,1998, pp.13-42.

Tötösy de Zepetnek, Steven, and Graciela Boruszko. "Paradigm Shift in Comparative Humanities: Digital Humanities, Pedagogy with New Media Technology, and Publishing Scholarship Online." The 2014-2015 Report on the State of the Discipline of Comparative Literature (2014).

Dominguez, Cesar. "Comparative Literary History: A Conversation with Marcel CornisPope and Margaret R. Higonnet." Futures of Comparative Literature: ACLA State of the Discipline Report, edited by Heise, Ursula K. et al., Routledge, 2017, pp. 35-48.

Dominguez, Cesar, et al. "Interartistic Comparison." Introducing Comparative Literature: New Trends and Applications. Routledge, 2015, pp. 107-24. https://doi.org/10.4324/9781315770987

Edmond, Jacob. "Archive of the Now." Futures of Comparative Literature: ACLA State of the Discipline Report, edited by Heise, Ursula K. et al., Routledge, 2017, pp.239-47.

Foster, Jr., John Burt. "Cultural Encounters in a Global Contexts: World Literature as a One-Semester General Education Course." Teaching World Literature, edited by David Damrosch, Modern Language Association of America, 2009, pp. 155-64.

Friedman, Susan Stanford. "Why not compare?" PMLA/Publications of the Modern Language Association of America, vol.126, no.3, 2011,pp.753-762. https://doi.org/10.1632/pmla.2011.126.3.753

Hayot, Eric. "Institutional Inertia and the State of the Discipline." Futures of Comparative Literature: ACLA State of the Discipline Report, edited by Heise, Ursula K. et al., Routledge, 2017, pp. 11-16.

Heise, Ursula. "Comparative Literature and Computational Criticism: A Conversation with Franco Moretti." Futures of Comparative Literature: ACLA State of the Discipline Report, edited by Heise, Ursula K. et al., Routledge. 2017, pp. 27384.

Hermans, Theo. "Literary Translation." The Companion to Translation Studies, edited by Piotr Kuhiwczak and Karin Littau, Clevedon, Buffalo, Toronto: Multilingual Matters Ltd. 2007, pp. 77-91.

Hitchcock, Peter. "The Ethics of World Literature." The Routledge Companion to World Literature, United States and Canada: Routledge, 2011, pp. 365-72. www.routledgehandbooks.com/doi/10.4324/9780203806494.ch37

Klein, Lucas. "Reading and Speaking for Translation: De-Institutionalizing the Institutions of Literary Study." In Futures of Comparative Literature: ACLA 
State of the Discipline Report, edited by Heise, Ursula K. et al. Routledge, 2017.

Mendoza, Amado Anthony. "Resil Mojares and the Crisis of Comparative Literature in the Philippines." Journal of Nusantra Studies, vol 3, no.2, 2018, pp. 80-91. http://dx.doi.org/10.24200/jonus.vol3iss2pp80-91

Mojares, Resil. "Inside Out, Outside In: Teaching World Literature Through Philippine Literature." Kritika Kultura, vol 24, no.1, 2015, pp. 229-39. http://dx.doi.org/10.13185/KK2015.02408

Prettiman, C.A. "' Literature That Changed the World': Designing a World Literature Course." Teaching World Literature, Edited by David Damrosch, Modern Language Association of America, 2009, pp. 377-84.

Puncher, Martin. "Teaching Worldly Literature." The Routledge Companion to World Literature, United States and Canada: Routledge, 2012, pp. 255-263. http://dx.doi.org/10.4324/9780203806494.ch37

Spivak, Gayatri and David Damrosch. Comparative Literature/World Literature: A Discussion with Gayatri Chakravorty Spivak and David Damrosch, Columbia University Libraries' Columbia Academic Commons. 2011. https://doi.org/10.5325/complitstudies.48.4.0455

Spivak, Gayatri. "The End of Languages." Futures of Comparative Literature: ACLA State of the Discipline Report, edited by Heise, Ursula K. et al, Routledge.2017, pp. 220-221.

Venuti, Lawrence. "Teaching in Translation." Teaching World Literature, edited by David Damrosch, Modern Language Association of America, 2009, pp. 86-98.

Wang, Ban. "Aesthetic Humanity and the Great World Community Kant and Kang Youwei." Futures of Comparative Literature: ACLA State of the Discipline Report, Edited by Heise, Ursula K. et al., Routledge, 2017, pp. 145-55.

Weifang, Li. "The Mission of Research on Globalization and Comparative Literature." Comparative Literature East and West, vol. 2 no. 1, 2018, pp.38-44. https://doi.org/10.1080/25723618.2018.1482684

\section{Honeylet L. Alerta}

\section{The Authors}

University of the Philippines Diliman

Email: hlalerta@up.edu.ph

\section{The Article}

Date Sent: 28/09/2021

Date Revised: 22/11/2021

Date Accepted: 23/11/2021 